\title{
Erratum to: QTLs for root traits at mid-tillering and for root and shoot traits at maturity in a RIL population of spring bread wheat grown under well-watered conditions
}

B. Ehdaie - S. A. Mohammadi •

M. Nouraein $\cdot$ H. Bektas $\cdot$ J. G. Waines

Published online: 4 July 2016

(C) Springer Science+Business Media Dordrecht 2016

\section{Erratum to: Euphytica \\ DOI 10.1007/s10681-016-1670-x}

Due to an unfortunate misunderstanding, two of the co-authors were omitted from the original publication and the research institutes were not properly acknowledged.

The correct acknowledgments, the representation of the authors and their affiliations are listed here and should be treated as definitive.

The online version of the original article can be found under doi:10.1007/s10681-016-1670-x.

B. Ehdaie $(\varangle) \cdot$ H. Bektas · J. G. Waines

Department of Botany and Plant Sciences, University of California, Riverside, CA 92521, USA

e-mail: bahman.ehdaie@ucr.edu

\section{S. A. Mohammadi}

Department of Plant Breeding and Biotechnology, Faculty of Agriculture, University of Tabriz, Tabriz, Iran

M. Nouraein

Department of Agronomy and Plant Breeding, Faculty of

Agriculture, University of Maragheh, Maragheh, Iran
Acknowledgments The research was financed by The California Wheat Commission, The University of CaliforniaRiverside Botanic Gardens, and the California Agricultural Experiment Station. 